\title{
Epilepsy-associated long-term mortality after aneurysmal subarachnoid hemorrhage \\ OPEN
}

Jukka Huttunen, MD

Antti Lindgren, MD,

$\mathrm{PhD}$

Mitja I. Kurki, PhD

Terhi Huttunen, MD,

$\mathrm{PhD}$

Juhana Frösen, MD, PhD

Timo Koivisto, MD, PhD

Mikael von und zu

Fraunberg, MD, $\mathrm{PhD}$

Arto Immonen, MD,

$\mathrm{PhD}$

Juha E. Jääskeläinen, MD, $\mathrm{PhD}^{*}$

Reetta Kälviäinen, MD, $\mathrm{PhD}^{*}$

Correspondence to

Dr. Huttunen:

jukka.huttunen@kuh.fi

Editorial, page 222

\section{ABSTRACT}

Objective: To elucidate the epilepsy-associated causes of death and subsequent excess longterm mortality among 12-month survivors of subarachnoid hemorrhage from saccular intracranial aneurysm (SIA-SAH).

Methods: The Kuopio SIA Database (kuopioneurosurgery.fi) includes all SIA-SAH patients admitted to the Kuopio University Hospital from its defined catchment population in Eastern Finland. The study cohort consists of 779 patients, admitted from 1995 to 2007, who were alive at 12 months after SIA-SAH. Their use of reimbursable antiepileptic drugs and the causes of death (ICD-10) were fused from the Finnish national registries from 1994 to 2014.

Results: The 779 12-month survivors were followed up until death $(n=197)$ or December 31, 2014, a median of 12.0 years after SIA-SAH. Epilepsy had been diagnosed in 121 (15\%) patients after SIA-SAH, and 34/121 (28\%) had died at the end of follow-up, with epilepsy as the immediate cause of death in 7/34 (21\%). In the 779 patients alive at 12 months after SIA-SAH, epilepsy was an independent risk factor for mortality (hazard ratio 1.8, 95\% confidence interval 1.1-3.0).

Conclusions: Comorbid epilepsy in 12-month survivors of SIA-SAH is associated with increased risk of death in long-term follow-up. Survivors of SIA-SAH require long-term dedicated follow-up, including identification and effective treatment of comorbid epilepsy to prevent avoidable deaths.

Neurology ${ }^{\circledR} 2017 ; 89: 263-268$

\section{GLOSSARY}

AED = antiepileptic drug; HR = hazard ratio; ICD-10 = 10th revision of the International Classification of Diseases; ILAE = International League Against Epilepsy; KUH = Kuopio University Hospital; NHI = National Health Insurance; SAH = subarachnoid hemorrhage; SIA = saccular intracranial aneurysm; SII = Social Insurance Institution.

Aneurysmal subarachnoid hemorrhage (SAH), almost always from a ruptured saccular intracranial aneurysm (SIA), affects the working-age population. ${ }^{1}$ Mortality after SIA-SAH is high, $22 \%$ at 1 month and $27 \%$ at 12 months in our series of 1,657 SIA-SAH patients, mainly due to poor clinical condition and signs of brain injury on admission. ${ }^{2}$ The effect of SIA-SAH and its sequelae in the CNS and cardiovascular system often cause long-term morbidity ${ }^{3,4}$ and mortality. ${ }^{5,6}$ The 12-month survivors face long-term excess mortality as compared to the general population, ${ }^{5,6} 12 \%$ at 15 years among 1,746 survivors and $17 \%$ at 20 years among 3,078 survivors in 2 Finnish IA registries. Data on the long-term neurologic/psychologic/social outcome are scarce. ${ }^{3,4,7}$

The Kuopio Intracranial Aneurysm Patient and Family Database (kuopioneurosurgery.fi) includes all patients with ruptured intracranial SIAs admitted to the Kuopio University Hospital (KUH) from its defined Eastern Finnish catchment population. ${ }^{8}$ Medical data from the nationwide registries, including the hospital diagnoses, use of prescribed medicines, and causes of

\footnotetext{
*These authors contributed equally to this work as co-last authors.

From Neurosurgery (J.H., A.L., M.I.K., T.H., J.F., T.K., M.v.u.z.F., A.I., J.E.J.) and Neurology (R.K.), KUH NeuroCenter, Kuopio University Hospital, and Faculty of Health Sciences, School of Medicine, Institute of Clinical Medicine, University of Eastern Finland, Kuopio.

Go to Neurology.org for full disclosures. Funding information and disclosures deemed relevant by the authors, if any, are provided at the end of the article. The Article Processing charge was funded by the authors.

This is an open access article distributed under the terms of the Creative Commons Attribution-NonCommercial-NoDerivatives License 4.0 (CC BY-NC-ND), which permits downloading and sharing the work provided it is properly cited. The work cannot be changed in any way or used commercially without permission from the journal.
} 
death, have been fused to the database..$^{2-5,9,10}$ The antidepressant use among 940 survivors was significantly higher (odds ratio 2.6) than in their 2,676 matched controls. ${ }^{4}$ The cumulative incidence of epilepsy was $12 \%$ at 5 years in 876 survivors, with intracerebral hemorrhage, poor condition on admission, and acute seizures as independent risk factors. ${ }^{3}$

Excess mortality after the diagnosis of symptomatic epilepsy is well-recognized, ${ }^{11-13}$ and it is referred, e.g., to epilepsy itself, treatment-related deaths, accidents, suicides, sudden unexpected death in epilepsy, and status epilepticus. ${ }^{14,15}$ No comprehensive and population-based studies are available on the long-term morbidity and mortality of the patients who survived SIA-SAH but developed epilepsy. In the present study, an extension to

Figure

\section{Flowchart of the identification of comorbid epilepsy and mortality after subarachnoid hemorrhage (SAH)}

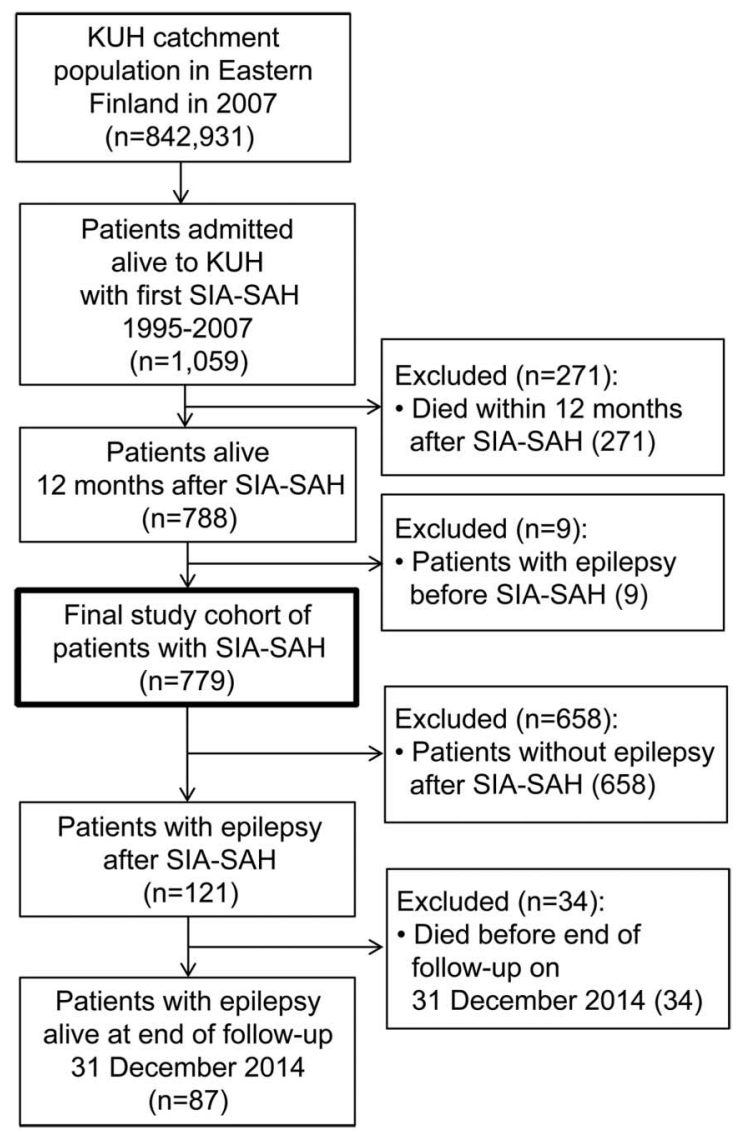

Flowchart of the identification of epilepsy and mortality after SAH from saccular intracranial aneurysm (SIA) among the 779 SIA-SAH patients alive at 12 months after admission to the Kuopio University Hospital (KUH) from its eastern Finnish catchment population. The 121 patients with newly diagnosed epilepsy after SIA-SAH were identified according to the reimbursement of physician-prescribed antiepileptic drugs in the nationwide registry. Statistics on causes of death and on the development of mortality was produced by Statistics Finland. our previous study, ${ }^{3}$ we compared the circumstances of deaths, including underlying and immediate causes of deaths, in the patients who died with epilepsy (34/121) or without epilepsy $(163 / 658)$ in a median follow-up of 12 years after SIA-SAH.

METHODS Catchment population of KUH. Since 1977, Neurosurgery of KUH has solely provided full-time acute and elective neurosurgical services for the KUH catchment population in Eastern Finland..$^{2-5}$ During the recruitment period of the present study, 1995 to 2014, the geographic area has remained the same. The population has decreased from 882,671 to 840,587 .

Admission of SAH patients to KUH. All cases of SAH diagnosed by CT or spinal tap at the KUH catchment area have been acutely admitted to KUH for angiography and treated if not moribund or very aged. The exact number of rejected SAH patients treated in non-neurosurgical units is not available.

Kuopio neurosurgery intracranial aneurysm patient and family database. The database includes all cases of unruptured and ruptured intracranial aneurysm patients admitted to KUH since 1980 (kuopioneurosurgery.fi). ${ }^{2-5,9,10}$ The database has been prospective since 1990. The database is run by a dedicated full-time research coordinator who interviews all new patients. ${ }^{2-5,9,10}$ The criteria for SIA family are at least 2 affected first-degree relatives, and SIA disease without family history is considered sporadic. ${ }^{8}$ The clinical data from the hospital periods and follow-up visits are coded into an extensive list of variables..$^{2-5,9,10}$ The use of prescribed medicines (see below), any hospital diagnoses, and causes of death have been entered from the Finnish nationwide registries. ${ }^{2-5,9,10}$

Study population of 779 12-month survivors of SIA-SAH. The inclusion criteria were as follows:

1. A citizen of Finland and resident of the KUH catchment area at the time of first SIA-SAH between January 1, 1995, and December 31, $2007^{3}$

2. Verification of SIAs by angiography

3. Alive at 12 months after acute admission for SIA-SAH

The exclusion criteria were rupture of an intracranial aneurysm other than a saccular one (e.g., fusiform, traumatic, mycotic) and previous diagnosis of epilepsy $(n=14) .{ }^{3}$ The figure presents the flow chart from the KUH catchment population to the final study cohort of 779 SIA-SAH patients.

Diagnosis of epilepsy among 779 12-month survivors of SIA-SAH. The National Health Insurance (NHI) scheme is part of the Finnish social security system, and it is run by the Social Insurance Institution (SII) of Finland. All permanent residents of Finland are covered under the NHI scheme. The SII maintains a nationwide registry for all patients who have been granted special reimbursement of medicines, including antiepileptic drugs (AEDs). In order to be reimbursed at the pharmacy for epilepsy, patients must submit a medical certificate to the SII. The medical certificate must be based on examinations and diagnosis of epilepsy made by a neurologist. The entitlement to special reimbursement of AEDs is granted by SII for noninstitutionalized patients. The following AEDs were reimbursed: carbamazepine, clobazam, clonazepam, gabapentin, lamotrigine, levetiracetam, nitrazepam, oxcarbazepine, phenobarbital, phenytoin, pregabalin, rufinamide, sodium valproate, stiripentol, tiagabine, topiramate, vigabatrin, and zonisamide. 
The data on fully reimbursed AEDs between January 1, 1994, and December 31, 2014, was integrated to the Kuopio SIA Database. The recruitment period of patients between January 1,1995, and December 31,2007, allowed data on the use of
AEDs for at least 1 year before SIA-SAH and at least 7 years after SIA-SAH (figure). ${ }^{3}$ Hospital diagnoses and case reports of identified epilepsy patients, from all neurology units in the KUH catchment area during the follow-up, were reviewed. None of

Table 1 Characteristics of 779 patients alive at 12 months after subarachnoid hemorrhage from saccular intracranial aneurysm (SIA-SAH) from a defined Eastern Finnish population between 1995 and 2014

\begin{tabular}{|c|c|c|c|c|}
\hline & \multicolumn{2}{|c|}{$\begin{array}{l}\text { Patients with no epilepsy } \\
\text { after SIA-SAH ( } n=658), n(\%)\end{array}$} & \multicolumn{2}{|c|}{$\begin{array}{l}\text { Patients with epilepsy after } \\
\text { SIA-SAH }(n=121), n(\%)\end{array}$} \\
\hline & All & 163 Deaths & All & 34 Deaths \\
\hline Median age at admission for SIA-SAH, y & 50 & 63 & 47 & 57 \\
\hline Male & 273 & $81(30)$ & 58 & $18(31)$ \\
\hline Female & 385 & $82(21)$ & 63 & $16(25)$ \\
\hline Familial SIA disease & 95 & $13(14)$ & 23 & $3(13)$ \\
\hline \multicolumn{5}{|l|}{ Location of ruptured SIA } \\
\hline AComA & 221 & $56(25)$ & 27 & $7(26)$ \\
\hline A2-A5 & 39 & $11(28)$ & 6 & 2 (33) \\
\hline M1 & 16 & $4(25)$ & 11 & $5(45)$ \\
\hline Mbif & 166 & $32(19)$ & 54 & $14(26)$ \\
\hline PComA & 86 & $36(42)$ & 14 & $2(14)$ \\
\hline PICA & 23 & 2 (9) & & \\
\hline ICAbif & 17 & $5(29)$ & 1 & $1(100)$ \\
\hline BAbif & 24 & $4(17)$ & 3 & $2(67)$ \\
\hline Others & 66 & $13(20)$ & 5 & $1(20)$ \\
\hline Two or more SIAs & 183 & $51(28)$ & 45 & $13(29)$ \\
\hline \multicolumn{5}{|l|}{ Hunt and Hess scale on admission } \\
\hline Grade I & 101 & $18(18)$ & 11 & $3(27)$ \\
\hline Grade II & 322 & $86(27)$ & 31 & $11(35)$ \\
\hline Grade III & 147 & $39(27)$ & 42 & $14(33)$ \\
\hline Grade IV & 76 & $18(24)$ & 29 & $6(21)$ \\
\hline Grade V & 12 & $2(17)$ & 8 & \\
\hline Intracerebral hematoma & 114 & $33(29)$ & 60 & 20 (33) \\
\hline Intraventricular hematoma & 121 & $34(28)$ & 30 & 7 (23) \\
\hline \multicolumn{5}{|l|}{ Acute hydrocephalus after SIA-SAH } \\
\hline Moderate & 236 & $70(30)$ & 39 & $14(36)$ \\
\hline Severe & 25 & $9(36)$ & 6 & $3(50)$ \\
\hline \multicolumn{5}{|l|}{ Occlusive therapy of ruptured SIA } \\
\hline Microsurgery & 409 & $94(23)$ & 96 & $28(29)$ \\
\hline Endovascular therapy & 541 & $63(12)$ & 21 & $5(24)$ \\
\hline Shunt for hydrocephalus after SIA-SAH & 86 & $35(41)$ & 25 & $10(40)$ \\
\hline Antidepressant use after SIA-SAH & 185 & $55(30)$ & 50 & $17(34)$ \\
\hline \multicolumn{5}{|l|}{ Glasgow Outcome Scale at 12 months } \\
\hline Good recovery & 501 & $104(21)$ & 60 & $17(28)$ \\
\hline Moderate disability & 114 & 37 (32) & 42 & $12(29)$ \\
\hline Severe disability & 37 & $16(43)$ & 18 & $5(28)$ \\
\hline Vegetative state & 6 & $6(100)$ & 1 & \\
\hline
\end{tabular}

Abbreviations: A2-A5 = A2-A5 segments of anterior cerebral artery; AComA = anterior communicating artery; BAbif = basilar artery bifurcation; ICAbif = internal carotid artery bifurcation; $\mathrm{M} 1$ = proximal segment of middle cerebral artery; Mbif = middle cerebral artery bifurcation; PComA = posterior communicating artery; PICA = posterior inferior cerebellar artery. 
the patients was lost to follow-up. The AED data contained information since the first purchase date, and the number of purchases, until the last date.

In our previous study ${ }^{3}$ and in the present study, the criteria for the epilepsy diagnosis after SIA-SAH in the AED users, evaluated by neurologists, followed the current International League Against Epilepsy (ILAE) definition ${ }^{16}:$ (1) at least 2 unprovoked seizures occurring $>24$ hours apart or (2) 1 unprovoked seizure and high probability of further seizures due to, for example, brain infarct, intracerebral hemorrhage, or status epilepticus. Acute seizures within 1 week after the onset of SIA-SAH were not considered as unprovoked seizures. ${ }^{17}$ Status epilepticus was defined as seizure duration of 30 minutes according to the ILAE guideline in $1993 .^{18,19}$

Causes of deaths among 779 12-month survivors of SIA-SAH. Statistics Finland produces statistics on all causes of death. The statistics on causes of death cover the persons who have died in Finland or abroad during the calendar year and who at the time of death were domiciled in Finland. This ensures complete identification of causes of death. The statistics are based on data in death certificates and causes of death; the statistics have been compiled according to the ICD-10 since 1996. Death certificate is a written description of the circumstances of the death produced by a physician. In death certificates, conditions contributing to death are reported in 2 parts: underlying cause of death and immediate cause of death, if determined, and the second part for other factors contributing to death. The death certificates data and causes of death on all patients who died before the end of follow-up on December 31, 2014, were integrated to the Kuopio SIA Database.

Circumstances and causes of death of 34 patients with epilepsy after SIA-SAH. For the 34 patients who died with epilepsy diagnosis after SIA-SAH, the certificates of death and all available clinical records were reviewed to reconstruct the circumstances of the deaths, including underlying causes of death and immediate causes of death, to analyze whether epilepsy was a contributing factor to the death.

Literature review. PubMed was searched for clinically relevant English articles since 1995 with the following search words: aneurysm* and (subarachnoid haemorrhage) and epilepsy and mortality.

Statistical analysis. The clinical variables of the SIA-SAH patients are presented in table 1. Discrete variables were expressed in proportions and continuous variables in medians, quartiles, and ranges. Groups were compared using the $\chi^{2}$ test or the MannWhitney $U$ or Kruskal-Wallis tests when appropriate. The independent risk factors for death were analyzed using the Cox proportional hazards regression. Epilepsy after SIA-SAH was treated as a time-dependent covariate in a Cox regression analysis. Other covariates in Cox regression analysis were age at admission, intracerebral haemorrhage from ruptured SIA, acute seizure within 1 week after admission, sex, and Hunt and Hess grade on admission. In the mortality analyses, the patients who died within 12 months from the rupture of SIA $(n=271)$ or epilepsy before SIA-SAH $(\mathrm{n}=9)$ were excluded. $p$ Values $<0.05$ were considered significant. IBM SPSS Statistics 22 (SPSS Inc., Chicago, IL) was used.

Standard protocol approvals, registrations, and patient consents. The study was approved by the Ethical Committee of KUH. Data integration from the national registries was performed with approval from the Ministry of Social Affairs and Health of Finland.

RESULTS Mortality of 779 patients alive 12 months after SIA-SAH with or without epilepsy. The final study cohort, 779 12-month survivors of SIA-SAH (figure, table 1), had been followed up for a median of 12 years after the time of SIA-SAH, a total follow-up of 9.394 patient-years. Epilepsy after SIA-SAH had been diagnosed in 121 patients, in a median time of 8 months after SIA-SAH (figure, table 1). Of the 121 epilepsy patients, 34 had died from 12 months until December 31, 2014, (figure) at median age of 66 years, a cumulative mortality of $7 \%$ at 5 years and $21 \%$ at 10 years. Of the 658 nonepilepsy patients, 163 had died at median age of 74 years, a cumulative mortality of $6 \%$ at 5 years, $16 \%$ at 10 years, and $28 \%$ at 15 years. 
Underlying and immediate causes of death of 34 epilepsy patients vs 163 nonepilepsy patients. Among the underlying causes of death (table 2), the category "external causes, injury, or poisoning" was more frequent in the 121 patients who developed epilepsy after SIA-SAH, but the difference between 5/34 deaths (15\%) vs $9 / 163$ deaths $(6 \%)$ was not statistically significant $(p=$ $0.07)$. Epilepsy was the immediate cause of death in $7 /$ 34 (21\%) patients; 4 of the deaths were associated with status epilepticus, 1 AED intoxication, and 2 seizurerelated pneumonias. In retrospect, epilepsy seemed to be associated with 12 (35\%) of the 34 deaths.

AED use by epilepsy patients. The 121 epilepsy patients had used AEDs from the date of epilepsy diagnosis until death or December 31, 2014, for a median time of 127 months; among them the 34 deceased for a median of 83 months until death. Among the 34 deceased, the median time from the last AED purchase to the death was 4 months; importantly, 12/34 (35\%) had not purchased AEDs within 12 months prior to death.

Independent risk factors for mortality after SIA-SAH. We studied whether epilepsy after SIA-SAH would be an independent risk factor of death by comparing the mortality in the 2 groups (34/121 vs 163/658; table $2)$. In Cox proportional hazards regression analysis, we also tested the 3 factors that independently predicted epilepsy in our previous study. ${ }^{3}$ The independent risk factor associated with death from any cause in the 779 12-month survivors of SIA-SAH were male sex (hazard ratio [HR] 2.0), advanced age (HR 1.1 per year), and epilepsy (HR 1.8) (table 3).

DISCUSSION We studied the epilepsy-related mortality among the survivors of SIA-SAH, with complete data for the underlying and immediate causes of death

\begin{tabular}{|c|c|c|c|c|}
\hline \multirow[t]{2}{*}{ Table 3} & \multicolumn{4}{|c|}{$\begin{array}{l}\text { Cox regression analysis of risk factors of mortality among } 779 \text { patients } \\
\text { alive } 12 \text { months after subarachnoid hemorrhage from saccular } \\
\text { intracranial aneurysm (SIA-SAH) between } 1995 \text { and } 2014\end{array}$} \\
\hline & & HR & p Value & $95 \% \mathrm{Cl}$ \\
\hline Male sex & & 2.0 & 0.000 & $1.5-3.0$ \\
\hline Age at ad & ssion for SIA-SAH (1-y increase) & 1.1 & 0.000 & $1.06-1.09$ \\
\hline \multicolumn{5}{|c|}{ Hunt and Hess scale on admission } \\
\hline Grade I & & 1.5 & NS & $1.0-2.5$ \\
\hline Grade II & & 1.1 & NS & $0.8-1.9$ \\
\hline Grade I & & 1.1 & NS & $0.6-2.1$ \\
\hline Grade I & & 0.6 & NS & $0.1-2.7$ \\
\hline \multicolumn{5}{|c|}{ Grade V } \\
\hline \multicolumn{2}{|c|}{ Intracerebral hematoma } & 1.3 & NS & $1.0-1.9$ \\
\hline \multicolumn{2}{|c|}{ Acute seizures within 1 week after admission } & 1.1 & NS & $0.7-1.7$ \\
\hline \multicolumn{2}{|c|}{ Epilepsy after SIA-SAH } & 1.8 & 0.015 & $1.1-3.0$ \\
\hline
\end{tabular}

Abbreviations: $\mathrm{Cl}=$ confidence interval; $\mathrm{HR}=$ hazard ratio; $\mathrm{NS}=$ not significant in a population-based cohort. In our previous analysis of 1,657 SIA-SAH patients, the mortality after acute SIA-SAH was $27 \%$ at 12 months, mainly due to poor clinical condition and signs of brain injury on admission; after 12 months, other causes of death than acute brain injury became more prevalent. ${ }^{2}$ In the present study, 121 of the 779 12-month SIA-SAH survivors had developed epilepsy, and they had used AEDs for a median of 127 months. Among these 121 patients, epilepsy was the immediate cause of 7 (21\%) of the 34 deaths, 4 of them related to status epilepticus. In our retrospective analysis, epilepsy was associated with a total of $12(35 \%)$ of the 34 deaths. The mechanisms with which epilepsy in AED-treated adult patients still causes excess mortality have not been fully elucidated. ${ }^{20}$ In our series, external causes of death (e.g., accident, intoxication, suicide) were more common in the 34 deceased epilepsy patients than in the 163 deceased nonepilepsy patients after SIA-SAH (table 2). In a recent study from Sweden with population and unaffected sibling controls, $16 \%$ of deaths in epilepsy patients were from external causes, with high odds for nonvehicle accidents and suicide. Of those who died from external causes, 75\% had comorbid psychiatric disorders, with strong associations with co-occurring depression and substance abuse. ${ }^{21}$ In Finland, prescriptions are valid for 1 year, while pharmacies give out medications for 3 months at one purchase. In the present cohort, the compliance of the 121 epilepsy patients for AED use was good in general. However, 12 (35\%) of the 34 deceased epilepsy patients had not purchased AEDs in the year prior to death. Poor compliance or sustainability of long-term AED treatment in epilepsy may be an avoidable risk factor for death in dedicated follow-up services for SIA-SAH survivors. Finland offers its residents publicly funded health care, which decreases socioeconomic differences in access to health care. Finland is divided into mutually exclusive catchment areas of tertiary care among the 5 university hospitals. ${ }^{2-5,9,10}$ The Finnish health care system allows the creation of disease cohorts that are unselected and minimally biased. ${ }^{2-5,9,10}$ Very accurate population statistics and a stable population allow long-term follow-up and ensure that few patients are lost to follow-up. ${ }^{2-5,9,10}$ Our study is retrospective, but we were able to confirm diagnoses of the patients with epilepsy by neurologists due to the national registry of fully reimbursed medicines and the causes of death produced by Statistics Finland. ${ }^{3}$ We did not have valid information about epilepsy in the patients permanently institutionalized after SIA-SAH. Their AEDs are not reimbursed but are included in the institution fees, so the overall incidence may be slightly underestimated. The survivors of SIA-SAH-whether sporadic or members of SIA families — would benefit from dedicated e-health services designed to improve the 
awareness of the disease and its risks and outcomes. Our present and previous data on epilepsy ${ }^{3}$ in SIA$\mathrm{SAH}$ survivors, as well as their long-term risks for depression, ${ }^{4}$ shunt-dependent hydrocephalus, ${ }^{22}$ and excess mortality, ${ }^{2,5}$ would support the development of accurate medical risk and outcome calculators for clinicians, patients and their relatives, and the general public. Such calculators are already found on the Internet for many diseases, but at best they should be supported by data from population-based neurodisease cohorts, with clinical lifelines constructed from followup and national registry data. Comorbid epilepsy in the 12-month survivors of SIA-SAH is associated with increased risk of death in long-term follow-up. Our present and previous data $^{3}$ on epilepsy in SIA-SAH survivors, as well as the risk of depression, ${ }^{4}$ suggests that dedicated evaluation and follow-up practices should be organized for SIA-SAH survivors. ${ }^{7}$

\section{AUTHOR CONTRIBUTIONS}

Dr. Huttunen: study design, funding acquisition, data acquisition, statistica analysis, drafting of the manuscript. Dr. Lindgren: statistical analysis, review of the manuscript. Dr. Kurki: review of the manuscript. Dr. Huttunen: review of the manuscript. Dr. Frösen: review of the manuscript. Dr. von und zu Fraunberg: data acquisition, statistical analysis, reviews of the manuscript. Dr. Koivisto: data acquisition, review of the manuscript. Dr. Immonen: study design, study supervision, review of the manuscript. Dr. Jääskeläinen: study design, study supervision, funding acquisition, review of the manuscript. Dr. Kälviäinen: study design, study supervision, review of the manuscript.

\section{STUDY FUNDING}

The study was supported by Finnish Academy of Sciences, Kuopio University Hospital, and UCB Nordic Epilepsy Grant.

\section{DISCLOSURE}

J. Huttunen has received funding from the UCB Nordic Epilepsy Grant. A. Lindgren, M. Kurki, T. Huttunen, J. Frösen, T. Koivisto, and M. von und zu Fraunberg report no disclosures relevant to the manuscript. A. Immonen has received funding for travel and speaker honoraria from UCB Pharma. J. Jääskeläinen reports no disclosures relevant to the manuscript. R. Kälviäinen has received speaker's honoraria from Eisai, UCB, and Orion; honoraria for membership of advisory boards/consultation from Eisai, Fennomedical, GW Pharmaceuticals, Orion, Pfizer, Sandoz, Sage, and UCB; and research support for her institute from the Academy of Finland, UCB, and Eisai. Go to Neurology.org for full disclosures.

Received December 9, 2016. Accepted in final form March 24, 2017.

\section{REFERENCES}

1. Nieuwkamp DJ, Vaartjes I, Algra A, Rinkel GJ, Bots ML. Risk of cardiovascular events and death in the life after aneurysmal subarachnoid haemorrhage: a nationwide study. Int J Stroke 2014;9:1090-1096.

2. Karamanakos PN, von Und Zu Fraunberg M, Bendel S, et al. Risk factors for three phases of 12-month mortality in 1657 patients from a defined population after acute aneurysmal subarachnoid hemorrhage. World Neurosurg 2012;78:631-639.

3. Huttunen J, Kurki MI, von Und Zu Fraunberg M, et al. Epilepsy after aneurysmal subarachnoid hemorrhage: a population-based, long-term follow-up study. Neurology 2015; 84:2229-2237.
4. Huttunen J, Lindgren A, Kurki MI, et al. Antidepressant use after aneurysmal subarachnoid hemorrhage: a population-based case-control study. Stroke 2016;47:2242-2248.

5. Huttunen $\mathrm{T}$, von und $\mathrm{Zu}$ Fraunberg M, Koivisto T, et al. Long-term excess mortality of 244 familial and 1502 sporadic one-year survivors of aneurysmal subarachnoid hemorrhage compared with a matched eastern Finnish catchment population. Neurosurgery 2011;68:20-27.

6. Huhtakangas J, Lehto H, Seppa K, et al. Long-term excess mortality after aneurysmal subarachnoid hemorrhage: patients with multiple aneurysms at risk. Stroke 2015;46: 1813-1818.

7. Rinkel GJ, Algra A. Long-term outcomes of patients with aneurysmal subarachnoid haemorrhage. Lancet Neurol 2011;10:349-356.

8. Huttunen T, von und zu Fraunberg M, Frosen J, et al. Saccular intracranial aneurysm disease: distribution of site, size, and age suggests different etiologies for aneurysm formation and rupture in 316 familial and 1454 sporadic eastern Finnish patients. Neurosurgery 2010;66:631-638.

9. Lindgren AE, Kurki MI, Riihinen A, et al. Hypertension predisposes to the formation of saccular intracranial aneurysms in 467 unruptured and 1053 ruptured patients in eastern Finland. Ann Med 2014;46:169-176.

10. Lindgren AE, Kurki MI, Riihinen A, et al. Type 2 diabetes and risk of rupture of saccular intracranial aneurysm in eastern Finland. Diabetes Care 2013;36:2020-2026.

11. Keezer MR, Bell GS, Neligan A, Novy J, Sander JW. Cause of death and predictors of mortality in a community-based cohort of people with epilepsy. Neurology 2016;86:704-712.

12. Neligan A, Bell GS, Johnson AL, Goodridge DM, Shorvon SD, Sander JW. The long-term risk of premature mortality in people with epilepsy. Brain 2011;134:388-395.

13. Nevalainen O, Ansakorpi H, Simola M, et al. Epilepsyrelated clinical characteristics and mortality: a systematic review and meta-analysis. Neurology 2014;83:1968-1977.

14. Forsgren L, Hauser WA, Olafsson E, Sander JW, Sillanpaa M, Tomson T. Mortality of epilepsy in developed countries: a review. Epilepsia 2005;46(suppl 11):18-27.

15. Jansson B, Ahmed N. Epilepsy and injury mortality in Sweden: the importance of changes in coding practice. Seizure 2002;11:361-370.

16. Fisher RS, Acevedo C, Arzimanoglou A, et al. ILAE official report: a practical clinical definition of epilepsy. Epilepsia 2014;55:475-482.

17. Beghi E, Carpio A, Forsgren L, et al. Recommendation for a definition of acute symptomatic seizure. Epilepsia 2010; 51:671-675.

18. Commission on Epidemiology and Prognosis: International League Against Epilepsy. Guidelines for epidemiologic studies on epilepsy. Epilepsia 1993;34:592-596.

19. Trinka E, Kalviainen R. 25 years of advances in definition, classification and treatment of status epilepticus. Seizure 2017;44:65-73.

20. Dalic L, Cook MJ. Managing drug-resistant epilepsy: challenges and solutions. Neuropsychiatr Dis Treat 2016;12:2605-2616.

21. Fazel S, Wolf A, Langstrom N, Newton CR, Lichtenstein P. Premature mortality in epilepsy and the role of psychiatric comorbidity: a total population study. Lancet 2013; 382:1646-1654.

22. Adams H, Ban VS, Leinonen V, et al. Risk of shunting after aneurysmal subarachnoid hemorrhage: a collaborative study and initiation of a consortium. Stroke 2016;47: 2488-2496. 


\section{Neurology}

Epilepsy-associated long-term mortality after aneurysmal subarachnoid hemorrhage Jukka Huttunen, Antti Lindgren, Mitja I. Kurki, et al.

Neurology 2017;89;263-268 Published Online before print June 14, 2017

DOI 10.1212/WNL.0000000000004113

\section{This information is current as of June 14, 2017}

\section{Updated Information \& Services \\ Supplementary Material}

\section{References}

Citations

Subspecialty Collections

Permissions \& Licensing

Reprints including high resolution figures, can be found at: http://n.neurology.org/content/89/3/263.full

Supplementary material can be found at: http://n.neurology.org/content/suppl/2017/06/29/WNL.0000000000004 113.DC1

This article cites 22 articles, 5 of which you can access for free at: http://n.neurology.org/content/89/3/263.full\#ref-list-1

This article has been cited by 1 HighWire-hosted articles: http://n.neurology.org/content/89/3/263.full\#\#otherarticles

This article, along with others on similar topics, appears in the following collection(s):

\section{All Epilepsy/Seizures}

http://n.neurology.org/cgi/collection/all_epilepsy_seizures

Cohort studies

http://n.neurology.org/cgi/collection/cohort_studies

Outcome research

http://n.neurology.org/cgi/collection/outcome_research

Subarachnoid hemorrhage

http://n.neurology.org/cgi/collection/subarachnoid_hemorrhage

Information about reproducing this article in parts (figures,tables) or in its entirety can be found online at:

http://www.neurology.org/about/about_the_journal\#permissions

Information about ordering reprints can be found online:

http://n.neurology.org/subscribers/advertise

Neurology $\mathbb{B}$ is the official journal of the American Academy of Neurology. Published continuously since 1951, it is now a weekly with 48 issues per year. Copyright Copyright @ 2017 The Author(s). Published by Wolters Kluwer Health, Inc. on behalf of the American Academy of Neurology. All rights reserved. Print ISSN: 0028-3878. Online ISSN: 1526-632X.

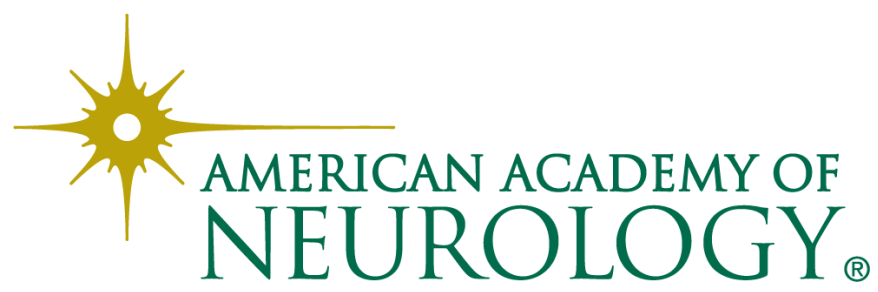

